\title{
Preface
}

The International scientific-practical conference "Agriculture and Food Security: Technology, Innovation, Markets, Human Resources" was successfully held at Kazan State Agrarian University (Kazan SAU) and Samara State Agrarian University (Samara SAU), Russia on May 28-30, 2020. The event was dedicated to the 70-th anniversary of the Institute of mechanization and technical service and the 90th anniversary of Kazan zoo-technical school.

\section{The organizers of the conference:}

Kazan State Agrarian University

Samara State Agrarian University

Kazan State Academy of Veterinary Medicine named after N. E. Bauman (KSAVM)

Ulyanovsk state agrarian university named after P. A. Stolypin (Ulyanovsk GAU)

\section{With the assistance of:}

Ministry of Agriculture and Food of the Russian Federation

Ministry of Agriculture and Food of the Republic of Tatarstan

Ministry of Agriculture and Food of the Samara Region

Branch of Agricultural Sciences of the Russian Academy of Sciences

Ministry of Education and Science of the Samara Region

Ministry of Education and Science of the Republic of Tatarstan

Academy of Sciences of the Republic of Tatarstan

Samara Scientific Center of the Russian Academy of Sciences

\author{
Associated partners: \\ FAO / Food and Agriculture Organization of the United Nations \\ Yüzüncü Y1l Universty / University of VAN (Turkey) \\ LOGO (Germany) \\ AMAZONEN-WERKE H (Germany)
}

The organizing committee of the conference received more than 150 applications for full-time participation and about 120 applications for correspondence participation. Scientific works were presented by researchers from various regions of the Russian Federation and other countries, namely: from Russian Federation (90\% of participants): Krasnodar Region, Volgograd Region, Vologda Region, Voronezh Region, Izhevsk Region, Kirov Region, Kemerovo Region, Moscow and Moscow Region, Ulyanovsk region, Ryazan region, Tver region, Novosibirsk region, Penza region, Samara region, Republics of Mari El and Bashkortostan, Buryatia. Foreign participants (10\% of participants): Germany, Turkey, USA, Finland, Portugal, Netherlands, Poland, Italy, Belarus, Kazakhstan, Tajikistan, Moldova, Uzbekistan.

Due to the difficult epidemiological situation around the world associated with the COVID-19 pandemic, the conference was held in a remote format using Zoom-conference technology.

On May 28, a plenary session was held. It was attended by more than 150 people, both at Kazan SAU and Samara SAU. A total of 19 plenary reports were presented.

On May 29, the work of 5 sections was organized, where more than 120 reports were presented, which reflected a wide range of issues related to different aspects of agronomy and crop production, agricultural production, food safety, and veterinary, issues of modern mechanization and technical service in agriculture, economy and personnel support of agriculture.

On May 30, the final plenary session was held, where the results were summed up and the certificates were presented to the participants.

\section{The participants of the conference}

note the positive and constructive experience of agrarian science, education and enlightenment in the Middle Volga region, represented, among other things, by the activities of such universities as Kazan SAU, Samara SAU, Ulyanovsk GAU and KSAVM; 
emphasize that today the consequences and impact of the COVID-19 pandemic on food security at the global and local level are the most serious, since in such conditions there is a decrease in food and economic security, a break in production and logistics ties of food, an increase in unemployment and an increase in the share of low-income citizens in conditions falling effective demand;

note that improved food security has a positive impact on trade, employment and improved living standards by reducing inequitable access to limited resources;

take into account that modern agricultural science and production requires the use of high and resourcesaving technologies that contribute to the rational use of natural resources, the development of modern methods of animal husbandry, the modernization and digitalization of mechanization and technical service processes, staffing of the agro-industrial complex in the digital economy;

deem it necessary to raise awareness at all levels and facilitate global events in support of food safety based on scientific principles in accordance with international and Russian standards.

As a result of the discussion, the following conference resolutions were represented:

- $\quad$ to use the successful experience of a number of agricultural educational and scientific institutions for the development of agricultural science and education in the Russian Federation;

- $\quad$ to increase the activity of joint research, including through participation in grants at various levels;

- $\quad$ to distinguish expansion of international relations, involvement of more young scientists and students in scientific and innovative activities as the most important directions of development of agricultural science;

- $\quad$ to promote the integration of intellectual efforts of scientists and scientific and pedagogical workers from different universities of Russia and abroad;

- to intensify research on the development of scientifically relevant, effective methods of disease prevention, increase animal productivity, formation of soil fertility;

- to initiate the creation of joint research teams to justify scientific approaches to the biologization of agricultural products;

- $\quad$ to promote the creation of technologies for the production of modern safe food products of a new generation using functionally valuable biologically active components of natural origin in order to develop environmentally safe food production;

- expand the comprehensive nature of research aimed at solving the problems of the development of digitalization of agriculture;

- $\quad$ to form practice programs based on a competent approach in the process of training and retraining of agricultural personnel in the framework of the application of digital technologies in agriculture;

- $\quad$ to use more widely the natural resource potential of the territories.

The participants of the conference consider it very useful and fruitful to exchange the experience of research work in the field of agriculture not only in Russia, but also in neighboring territories, taking into account the peculiarities of socio-economic, cultural and historical development, and international experience. It is important to promote the results of the conference among students and pupils in order to deepen the young generation's understanding of changes in the environment, agricultural and socio-cultural sphere.

At last, we would like to thank all the participants and conference organizers as well as reviewers and editors for their invaluable contribution in preparing the conference proceedings.

With the kindest regards, Committee Members 